\title{
Tips for charting the course of a successful health research career
}

This article was published in the following Dove Press journal:

Journal of Multidisciplinary Healthcare

23 April 2013

Number of times this article has been viewed

\section{Lawrence Mbuagbaw ${ }^{1-3}$ \\ Frederick Morfaw ${ }^{4}$ \\ John-Eudes L Kunda ${ }^{5}$ \\ Jackson K Mukonzo ${ }^{6}$ \\ Jasmine Kastner ${ }^{7}$ \\ Shiyuan Zhang ${ }^{2,3}$ \\ Madzouka Kokolo8 \\ Lehana Thabane 1,3,9-11 $^{-1}$}

'Centre for Development of Best Practices in Health, Yaounde Central

Hospital, Yaounde, Cameroon;

2Department of Clinical Epidemiology

and Biostatistics, McMaster University,

${ }^{3}$ Biostatistics Unit, Father Sean

O'Sullivan Research Centre,

St Joseph's Healthcare, Hamilton,

ON, Canada; ${ }^{4}$ Department of

Obstetrics and Gynaecology, Faculty

of Medicines and Biomedical Sciences,

University of Yaounde I, Yaounde,

Cameroon; ${ }^{5}$ Community Information

and Epidemiological Technologies,

Lusaka, Zambia; ${ }^{6} \mathrm{~S} c h o o l$ of Biomedical

Sciences, College of Health Sciences, University of Makerere, Kampala,

Uganda; 'Faculty of Health Sciences,

Simon Fraser University, BC, Canada;

${ }^{8}$ Ottawa Hospital Research Institute,

${ }^{9}$ Departments of Pediatrics and

Anaesthesia, McMaster University,

${ }^{10}$ Centre for Evaluation of Medicine,

St Joseph's Healthcare, "Population

Health Research Institute, Hamilton

Health Sciences, Hamilton, ON,

Canada

Correspondence: Lawrence Mbuagbaw Department of Clinical Epidemiology and Biostatistics, McMaster University, 1280 Main Street West, HSC 2C7,

Hamilton, ON, L8S4KI, Canada

Tel +90 55259140 ext 22430

Email mbuagblc@mcmaster.ca
Abstract: Young health researchers all over the world often encounter difficulties in the early stages of their careers. Formal acquisition of research skills in academic settings does not always offer sufficient guidance to overcome these challenges. Based on the collective experiences of some young researchers and research mentors, we describe some tips for a successful health career and offer some useful resources. These tips include: institutional affiliation, early manuscript writing, early manuscript reviewing, finding a mentor, collaboration and networking, identifying sources of funding, establishing research interests, investing in research methods training, developing interpersonal and personal skills, providing mentorship, and balancing work with everyday life. The rationale behind these tips and how to achieve them is provided.

Keywords: health research career, young researcher, guidance

\section{Introduction}

Many young researchers enter a career in health research with little guidance about the expectations and challenges awaiting them. There is often no set career path, and limited leadership to help guide youth. Inadequate training in specific research skills is a major factor limiting the level of research productivity and consequently health in developing countries. ${ }^{1}$ This is especially true in sub-Saharan Africa where resources and skills are limited. ${ }^{2}$ Yet these are not the only requirements for a successful research career. Skills learnt in the classroom cannot be transformed into output without help. Young researchers require guidance on how to steer their way to success in a career of health research. The literature is rife with research capacity building initiatives in Africa and other parts of the world, ${ }^{2-5}$ but these papers do not address how a young researcher can approach a career in health research and enhance his or her chances of success beyond formal training. Even though the main focus of research capacity building is in developing countries, ${ }^{6}$ in developed countries, where there are considerably more training institutions for health research, career paths may still be unclear. A successful research career requires having specific content knowledge and skills to conduct research, including socialization with the global research environment along with mentor, peer, and organizational support. ${ }^{7}$ In this paper, based on the collective experiences of some young researchers and research mentors, we discuss some factors that can help young researchers to achieve their maximum potential, and where possible, we point to useful resources.

\section{Get institutional affiliation}

Institutional affiliation is important for any young researcher. This includes maintaining a professional relationship with university professors and researchers, as well as possible 
affiliations with research centers or other professional centers (eg, clinical settings). This can be a gateway to professional recognition, particularly if the institution has a good reputation. For instance, access to an institutional email address and electronic network system can indicate credibility and facilitate safe storage and exchange of information and data. Likewise research funds from donors can only be administered through trustworthy institutions. Belonging to a research institution also exposes the young researcher to senior researchers and best practices, especially if the institution is an established center of excellence. Many centers for excellence have been established in African countries to promote the transfer of research skills from North to South and within the continent. ${ }^{8,9}$ Many such centers can be found in developed countries.

Generally speaking, institutional affiliation often comes with opportunities for training, along with the benefits of working in an environment with quality assurance, infrastructure, and formal administrative services. In addition, institutional affiliation may facilitate access to published research through institutional subscriptions, and cover article processing charges. In order to create such contacts, young researchers should investigate volunteer opportunities within such centers. There is a three-fold benefit to this. First, it exposes young researchers to the professional research environment. Secondly, it creates an "in" where volunteers can learn about position vacancies. Finally, a successful volunteer term will generate good references for future job applications.

\section{Start writing early}

The penultimate outcome of research is scientific publication, such that novel findings can be shared and used to improve knowledge and health. Strong writing skills are important to career development and success. A mastery of the skills required for prolific authorship (including language accuracy, technical accuracy, structured discourse, and conciseness) need to be acquired early. It is unlikely that one can acquire all the skills required for scientific writing without practice, hence the earlier the young researcher experiences the hurdles and work load involved in manuscript preparation, the better. Firsthand experience with manuscript formatting, referencing, determining authorship, reporting data, and undergoing peer review are important steps towards a career in research. A number of resources and guidelines exist for reporting medical research and preparing for publication that will prove invaluable to any young researcher. ${ }^{10-14}$ Young health researchers are encouraged to use these resources.
However, these skills cannot be put to use if time is not allocated for writing. It is necessary to reserve uninterrupted time to write research manuscripts. ${ }^{15}$

\section{Start reviewing early}

For the sake of fairness, some people recommend reviewing as many articles as you publish as a way of giving back to the scientific community. ${ }^{16}$ Although it is usually an unpaid activity, this is important because the peer review process is indispensable to the production of scientific research. ${ }^{17,18}$ Therefore, a young researcher interested in scientific publication should try to find ways to participate in the peer review process. With proper leadership, young researchers should be progressively introduced to the practice of peer review because it offers several advantages, including but not limited to: understanding the biomedical editorial process, honing their own skills in scientific writing and appraisal, staying abreast with current science, seeing other writing styles, learning from others' mistakes, contributing to the quality of published literature, and gaining recognition in the scientific community. Due to the volume of biomedical publications, there is a constant need for scientists willing to contribute their time and expertise as peer reviewers. It is also an important opportunity to reflect on one's own writing skills, and to recognize strengths and weaknesses. Guided initiation into peer reviewing is an invaluable component of growth as a researcher and it provides the opportunity to articulate clear and constructive feedback. One way of objectively reviewing an article is assessing whether it is written according to recommended guidelines. The EQUATOR (Enhancing the Quality and Transparency of Health Research) network is a good source of guidelines for reporting health research studies (http://www.equatornetwork.org/). Likewise, many journals, such as the British Medical Journal have guidance for reviewers which can be applied to any other journal (http://www.bmj.com/about-bmj/ resources-reviewers/guidance-peer-reviewers). Open access tips for reviewing have also been published. ${ }^{19}$

\section{Find a mentor}

It is important to distinguish between a supervisor and a mentor. Supervisory roles are often limited in time and commitment, usually leading to distinct academic outcomes or professional goals. On the other hand, a mentor and mentee negotiate their expectations and goals and use a wide variety of skill transfer techniques to achieve them, often for extended periods. The benefits of mentoring have been reported in numerous research settings, and include a greater 
likelihood of publishing, better academic and career growth, higher research productivity, and a genuine opportunity to learn skills that cannot be achieved through formal channels. ${ }^{15,20-22}$ Nowadays, with improved communication facilities worldwide, a young researcher can expand his or her pool of potential mentors to distant geographic regions. A framework for such long distance mentorship initiatives has been described. ${ }^{23}$ In addition to the direct knowledge transfer that occurs between a mentor and a mentee, the mentor can also introduce the mentee to a wider network of collaborators in different disciplines. ${ }^{23,24}$ There is some guidance on what mentors, mentees and institutions can do to foster mentoring relationships. ${ }^{24,25}$ Local training and leadership is beneficial and should be a primary source of mentorship. This will enable young researchers to learn directly from established researchers, their environments, and how they negotiate donor expectations. Mentorship is not without drawbacks, and it is crucial to establish a mechanism to determine when such relationships are not working well.

\section{Start collaboration and networking}

It is important for young researchers to realize early in their careers that collaboration, networking, and multidisciplinary team efforts are important. ${ }^{26}$ Networking is often one of the most stressful elements of expanding a career for young researchers. In regards to multidisciplinary projects, there is sometimes a power divide and confusion around the expectations of the role of each of the disciplines in the final product. Even though there may be sources of conflict, there is room for sharing of ideas and resources, making methodologies more robust and opening additional research and career opportunities. Collaboration can be with peers, senior, or junior colleagues. Apart from research activities conducted with senior colleagues, supervisors and mentors, young researchers can initiate preliminary attempts at sharing knowledge and guiding junior colleagues. Establishing networks with peers is also important at an early stage in one's career, and such networks may be long-lasting because they are between researchers at the same stage in their careers. Networks can be established electronically as well. Websites such as LinkedIn (http://www.linkedin. com/), Research Gate (http://www.researchgate.net), and many others provide a forum for like-minded professionals to meet and share ideas.

From a practical point of view, in quantitative research, collaboration with a biostatistician is always beneficial for both parties. Involving stakeholders in research question formulation and study design is also helpful, and experts should be consulted when necessary.

In a similar manner, young African researchers should not only seek collaborations in the North, but also within Africa. South-South collaborations are often lacking, and may evolve favorably without the complexities of power imbalances and donor-driven agendas. Such collaborations are often encouraged, ${ }^{1,27}$ but are likely to develop initially from personal networks. Young researchers in the North may also seek collaborations in the South.

\section{Identify sources of funding}

Research costs money. Developing skills in identifying funding sources and writing grant proposals are crucial for any young researcher. Young researchers must be aware of and up-to-date with the available funding bodies, including their focus and eligibility criteria. Networking is always a good way of getting to know about funding opportunities, but nowadays, funders typically have websites and can be found by Internet-based searches. Signing up for mailing lists of some advocacy groups, which are usually free, can also allow young researchers to receive updates automatically on available grants. Funding may be available for masters or doctoral studies, fellowships, or field research. Others are stand-alone grants and awards for earmarked research in specific domains or offered only to young researchers. Some of the more popular funders include: Wellcome Trust, Canadian Institutes for Health Research, United States National Institutes of Health, International Development Research Centre, United Kingdom Department for International Development, Centers for Disease Control and Prevention, and the Bill and Melinda Gates Foundation. A number of articles have been published on grant writing tips. $^{28-30}$ Ultimately, grant proposal writing is a skill, and similar to writing good papers, young researchers should seize every opportunity to practice early and often.

\section{Establish research interests}

Research interests often spawn from one's own background. For instance, surgical residents are more likely to be interested in surgical research. However, one may be interested in exploring a diversity of scientific questions within the same area or across disciplines. Focusing research interest gives the young researcher an opportunity to master specific research domains, tools, and methods, and to become familiar with pertinent networks and resources. We do not recommend a very narrow focus early on in the young researcher's career, but advise any young researcher to avoid being a "jack of 
all trades". In order to secure funding, academic positions, employment, or promotion, the young researcher will often have to describe his or her research interests and demonstrate refined skills in a specific area of interest. In a similar way, the young researcher can become established as an expert in a specific field. It is often easy to identify a clear research focus in "successful" researchers. Initial steps, such as reading senior faculty researcher profiles and writing and sharing drafts of research interest can help young researchers tremendously.

\section{Invest in developing research methods training}

Any formal training in research methods is an added advantage to content expertise. Important concepts such as formulation of a research question, study design, sample size requirements, basic biostatistics, and research ethics can often make a difference between publishable manuscripts and fatally flawed ones. More importantly, poorly designed and conducted research would potentially jeopardize a young researcher's reputation and self-confidence, the safety of participants involved in the research, the possibility to acquire more funds in the future, and the reputation of the institution. This often results in wastage of limited resources. Young researchers are invited to consider all the available options, such as short courses, online resources, and master's and doctoral studies. Within institutions, young researchers can organize journal clubs to learn from one another. ${ }^{24}$ Table 1 is a non-exhaustive list of free online resources.

\section{Develop an adequate set of interpersonal and personal skills}

Interpersonal skills are important in research. This is directly linked to networking abilities. Young researchers should be able to interact with other people in a social gathering to learn and share their ideas, make scientific oral and poster presentations fluently, and develop networks and collaborations with new acquaintances. They should always be ready to provide their contact details and request contact information from others. Likewise, personal skills, such as time management, are critical to meeting deadlines, which are a frequent requirement in the world of research, alongside other professional nonresearch activities. ${ }^{31}$ Firmness of purpose is also important when facing rejection of grant applications or manuscripts. A number of resources are available to guide researchers on how to deal with rejection. . $^{32,33}$

\section{Become a mentor}

The natural aspiration and evolution of a mentee should be to become a mentor, in turn. Young researchers should aim to obtain positions requiring academic or practical teaching and supervision. Mentoring is a rewarding academic and personal venture. ${ }^{34}$ This will provide the young researcher with opportunities to transmit the knowledge they have received and the expertise they have developed. This significantly contributes to capacity building and the sustainability of research. Evolving into a mentor is a desirable outcome in a former mentee. ${ }^{23}$

\section{Find and maintain balance}

As exciting and rewarding as research might be, it typically is only one part of a young researcher's professional activities, and it is only a part of one's life. As one's expertise grows, solicitations and responsibilities multiply. This may be a sign of recognition, but it also increases the risk of burnout. It is crucial to learn how to set priorities, and plan and organize one's life accordingly, so as to balance duties and necessities. ${ }^{15}$ Burnout can occur early in one's career, even during training, and have deleterious effects on job satisfaction and personal well-being. ${ }^{31}$

Table I Free online research resources

\begin{tabular}{|c|c|c|}
\hline Source & Course topic & URL (accessed on February 20, 2013) \\
\hline Tri-Council Policy Statement: Ethical & Research ethics & http://tcps2core.ca/welcome \\
\hline \multicolumn{3}{|l|}{ Conduct for Research Involving Humans } \\
\hline Unite for Sight, Global Health University & Global health research and other topics & $\begin{array}{l}\text { http://www.uniteforsight.org/global-health- } \\
\text { university/courses }\end{array}$ \\
\hline The Cochrane Collaboration & Systematic reviews & http://handbook.cochrane.org/ \\
\hline Carnegie Mellon University & Empirical research methods & $\begin{array}{l}\text { http://oli.cmu.edu/courses/future/empirical- } \\
\text { research-methods/ }\end{array}$ \\
\hline Training and Resources in Research & Research ethics & http://elearning.trree.org/ \\
\hline Ethics Evaluation & Good clinical practice & \\
\hline World Health Organisation/Health & Authorship skills & http://www.who.int/hinari/training/ \\
\hline InterNetwork Access to Research Initiative & & authorshipskills/en/index.html \\
\hline Duke University Global Health Institute & Standard operating procedures for clinical trials & http://globalhealth.duke.edu/resources/sops \\
\hline
\end{tabular}


Table 2 Tips for a successful research career

\begin{tabular}{|c|c|c|}
\hline Guidelines & Rationale & How to achieve \\
\hline Institutional affiliation & $\begin{array}{l}\text { - Resources } \\
\text { - Training opportunities } \\
\text { - Exposure to best practices } \\
\text { - Recognition } \\
\text { - Credibility } \\
\text { - Infrastructure }\end{array}$ & $\begin{array}{l}\text { - Maintain contact with previous educational } \\
\text { institutions } \\
\text { - Volunteer work } \\
\text { - Formally request affiliation }\end{array}$ \\
\hline Writing early & $\begin{array}{l}\text { - Necessity of research } \\
\text { - Experience can be gained } \\
\text { - Recognition }\end{array}$ & $\begin{array}{l}\text { - Learn by doing } \\
\text { - Use scientific writing resources }\end{array}$ \\
\hline Reviewing early & $\begin{array}{l}\text { - Fairness } \\
\text { - Learning opportunity } \\
\text { - Staying abreast with science }\end{array}$ & $\begin{array}{l}\text { - Progressive introduction by senior researcher } \\
\text { - Use peer reviewing resources }\end{array}$ \\
\hline Find a mentor & $\begin{array}{l}\text { - Academic growth } \\
\text { - Professional growth } \\
\text { - Research productivity }\end{array}$ & $\begin{array}{l}\text { - Join mentorship programs } \\
\text { - Actively seek mentorship }\end{array}$ \\
\hline Collaboration and networking & $\begin{array}{l}\text { - Establishing relationships } \\
\text { - Enhances research quality } \\
\text { - Creates more openings }\end{array}$ & $\begin{array}{l}\text { - Be open to collaboration } \\
\text { - Seek and offer help } \\
\text { - Use electronic forums for networking } \\
\text { - Attend relevant research meetings }\end{array}$ \\
\hline Funding & $\begin{array}{l}\text { - Necessary for research } \\
\text { - Necessary for training }\end{array}$ & $\begin{array}{l}\text { - Use networks to seek opportunities } \\
\text { - Subscribe to mailing lists }\end{array}$ \\
\hline Establish research interests & $\begin{array}{l}\text { - Provides a career focus } \\
\text { - Gives room for specialization }\end{array}$ & $\begin{array}{l}\text { - Identify your zone of comfort and research } \\
\text { interest } \\
\text { - Seek ways to contribute to this field and } \\
\text { enhance your skills }\end{array}$ \\
\hline Research methods training & $\begin{array}{l}\text { - Formal requirement for conducting research } \\
\text { and securing employment } \\
\text { - Ensures safer research }\end{array}$ & $\begin{array}{l}\text { - Formal education } \\
\text { - Free resources } \\
\text { - Research meetings }\end{array}$ \\
\hline Interpersonal and personal skill & $\begin{array}{l}\text { - Enhances communication and networking } \\
\text { - Necessary to market one's self and to } \\
\text { report research }\end{array}$ & $\begin{array}{l}\text { - Can be gained in a mentoring relationship } \\
\text { - Seek resources for specific skills like time } \\
\text { management and resilience }\end{array}$ \\
\hline Mentoring & $\begin{array}{l}\text { - Ensure sustainability of knowledge transfer } \\
\text { - Personally and professionally rewarding }\end{array}$ & $\begin{array}{l}\text { - Participate in formal mentorship programs } \\
\text { - Identify junior colleagues who need help }\end{array}$ \\
\hline Find and maintain balance & $\begin{array}{l}\text { - Key for stable family relationships } \\
\text { - Provides room for other activities in life }\end{array}$ & $\begin{array}{l}\text { - Practice time management } \\
\text { - Set specific achievable objectives }\end{array}$ \\
\hline
\end{tabular}

\section{Putting it all together}

The above guidelines are presented individually, but are interrelated. A young researcher may find a mentor in the institution to which he or she is affiliated and will probably engage in manuscript writing and peer reviewing. Personal and interpersonal skills are some of the nonacademic traits that one can learn from a mentor. Also, belonging to an institution may expose the young researcher to the funding mechanisms in play and how to obtain and manage funds. We emphasize that research involves a lot of "learning by doing", and that the earlier these steps are initiated, the greater the likelihood of success. Young health researchers are encouraged to develop the domains in which they are deficient. From a broader perspective, all of these factors can be facilitated and supported by research institutions by creating environments conducive for career enhancement and research productivity. Table 2 is a summary of the points outlined above.

\section{Concluding remarks}

Using a commentary style, we have provided some guidance that we hope young researchers can use to enhance their careers. The ideas are mostly based on our collective experience as junior researchers and research mentors, and each of us has utilized some or all of these strategies at some point in our research development path.

\section{Acknowledgment}

This paper is supported in part by the Canadian Institutes of Health Research (CIHR) Canadian HIV Trials Network (CTN) and the Canadian Network and Centre for Trials Internationally (CANNeCTIN) program. 


\section{Disclosure}

The authors report no conflicts of interest in this work.

\section{References}

1. Volmink J, Dare L. Addressing inequalities in research capacity in Africa. BMJ. 2005;331:705-706.

2. Kabiru CW, Izugbara CO, Wambugu SW, Ezeh AC. Capacity development for health research in Africa: experiences managing the African Doctoral Dissertation Research Fellowship Program. Health Res Policy Syst. 2010;8:21.

3. Marjanovic S, Hanlin R, Diepeveen S, Chataway J. Research capacity-building in Africa: networks, institutions and local ownership. J Int Dev. Published online July 12, 2012. Available from: http:// onlinelibrary.wiley.com/doi/10.1002/jid.2870/abstract. Accessed March 19, 2013.

4. Minja H, Nsanzabana C, Maure C, et al. Impact of health research capacity strengthening in low- and middle-income countries: the case of WHO/TDR programmes. PLoS Negl Trop Dis. 2011;5:e1351.

5. Felknor SA, Delclos GL, Gimeno D, et al. Funding of pilot projects in Latin America: a tool for capacity building in occupational health research. Int J Occup Environ Health. 2006;12:408-414.

6. Nchinda TC. Research capacity strengthening in the South. Soc Sci Med. 2002;54:1699-1711.

7. Bland CJ, Schmitz CC. Characteristics of the successful researcher and implications for faculty development. Acad Med. 1986;61:22-31.

8. Matee MI, Manyando C, Ndumbe PM, et al. European and Developing Countries Clinical Trials Partnership (EDCTP): the path towards a true partnership. BMC Public Health. 2009;9:249.

9. World Health Organisation. 32 new African Centres of Excellence named. Available from: http://www.who.int/tdr/news/2011/africancentres-excellence/en/index.html. Accessed March 19, 2013.

10. Shidham VB, Pitman MB, Demay RM. How to write an article: preparing a publishable manuscript! Cytojournal. 2012;9:1.

11. Ohwovoriole AE. Writing biomedical manuscripts part I: fundamentals and general rules. West Afr J Med. 2011;30:151-157.

12. Ohwovoriole AE. Writing biomedical manuscripts Part II: Standard elements and common errors. West Afr J Med. 2011;30:389-399.

13. Simera I, Moher D, Hoey J, Schulz KF, Altman DG. The EQUATOR Network and reporting guidelines: helping to achieve high standards in reporting health research studies. Maturitas. 2009;63:4-6.

14. Bourne PE. Ten simple rules for getting published. PLoS Comput Biol. 2005;1(5):e57.

15. Sackett DL. On the determinants of academic success as a clinician-scientist. Clin Invest Med. 2001;24:94-100.

16. Bourne PE, Barbour V. Ten simple rules for building and maintaining a scientific reputation. PLoS Comput Biol. 2011;7:e1002108.
17. Voight ML, Hoogenboom BJ. Publishing your work in a journal: understanding the peer review process. Int J Sports Phys Ther. 2012; 7: 452-460.

18. Thomas SP. Conceptual debates and empirical evidence about the peer review process for scholarly journals. J Prof Nurs. 2011;27:168-173.

19. Bourne PE, Korngreen A. Ten simple rules for reviewers. PLoS Comput Biol. 2006;2:e110.

20. Matovu JK, Wanyenze RK, Mawemuko S, et al. Building capacity for HIV/AIDS program leadership and management in Uganda through mentored Fellowships. Glob Health Action. 2011;4:5815.

21. Long-distance relationships. Nat Neurosci. 2007;10:1223.

22. Eby LT, Allen TD, Evans SC, Ng T, Dubois D. Does mentoring matter? A multidisciplinary meta-analysis comparing mentored and non-mentored individuals. J Vocat Behav. 2008;72:254-267.

23. Mbuagbaw L, Thabane L. How to set-up a long-distance mentoring program: a framework and case description of mentorship in HIV clinical trials. J Multidiscip Healthc. 2013;6:17-23.

24. Odueyungbo A, Thabane L. Mentoring in biostatistics: some suggestions for reform. J Multidiscip Healthc. 2012;5:265-272.

25. Thabane L, Thabane M, Goldsmith $\mathrm{CH}$. Mentoring young statisticians: facilitating the acquisition of important survival skills. Afr Stat $J$. 2006;2:31-42.

26. Kahn J, Des Jarlais CD, Dobkin L, Barrs SF, Greenblatt RM. Mentoring the next generation of HIV prevention researchers: a model mentoring program at the University of California San Francisco and Gladstone Institute of Immunology and Virology Center for AIDS research. J Acquir Immune Defic Syndr. 2008;47 Suppl 1:S5-S9.

27. Whitworth JAG, Kokwaro G, Kinyanjui S, et al. Strengthening capacity for health research in Africa. Lancet. 2008;372:1590-1593.

28. Inouye SK, Fiellin DA. An evidence-based guide to writing grant proposals for clinical research. Ann Intern Med. 2005;142:274-282.

29. Woodward DK, Clifton GD. Development of a successful research grant application. Am J Hosp Pharm. 1994;51(6):813-822.

30. Bourne PE, Chalupa LM. Ten simple rules for getting grants. PLoS Comput Biol. 2006;2:e12.

31. Sackett DL. Clinician-trialist rounds: 1. Inauguration, and an introduction to time-management for survival. Clin Trials. 2010;7:749-751.

32. Szatmari P, Sackett DL. Clinician-trialist rounds: 11 . When your grant gets turned down - part 1: remorse, anger, and reconciliation. Clin Trials. 2012;9:447-449.

33. Szatmari P, Sackett DL. Clinician-trialist rounds: 12 . When your grant gets turned down - part 2: resurrection. Clin Trials. 2012;9:660-663.

34. Allen TD, Poteet ML, Burroughs SM. The mentor's perspective: A qualitative inquiry and future research agenda. J Voc Behav. 1997;51:70.c-89.c
Journal of Multidisciplinary Healthcare

\section{Publish your work in this journal}

The Journal of Multidisciplinary Healthcare is an international, peerreviewed open-access journal that aims to represent and publish research in healthcare areas delivered by practitioners of different disciplines. This includes studies and reviews conducted by multidisciplinary teams as well as research which evaluates the results or conduct of such teams or

\section{Dovepress}

healthcare processes in general. The journal covers a wide range of areas and welcomes submission from practitioners at all levels, from all over the world. The manuscript management system is completely online and includes a very quick and fair peer-review system. Visit http://www.dovepress.com/testimonials.php to read real quotes from published authors. 